\title{
Transition from Junior to Senior Residency in Emergency Medicine: Requirements, Challenges and Recommendations
}

\author{
Fatimah Lateef*, FRCS (A\&E), MBBS, FAMS (Em Med) \\ Senior Consultant, Dept of Emergency Medicine, Singapore General Hospital \\ Professor, Duke NUS Graduate Medical School \\ Professor, Yong Loo Lin School of Medicine, National University of Singapore \\ Director, SingHealth Duke NUS Institute of Medical Simulation (SIMS), Singapore
}

\author{
*Corresponding author: Fatimah Lateef, FRCS (A\&E), MBBS, FAMS (Em Med), Senior \\ Consultant \\ Dept of Emergency Medicine, Singapore General Hospital \\ Professor, Duke NUS Graduate Medical School \\ Professor, Yong Loo Lin School of Medicine, National University of Singapore \\ Director, SingHealth Duke NUS Institute of Medical Simulation (SIMS)
}

Received Date: December 22, 2020

Published Date: January 20, 2021

\begin{abstract}
Residencies in Emergency Medicine (EM) teach the fundamental skills, knowledge and humanistic qualities that make up the fundamentals of the practice of EM. EM residents are nurtured to develop clinical confidence and maturity, sound judgment, as well as technical skills and capabilities. The training encompasses several domains, namely, medical knowledge, patient care, communications, professionalism, evidence-based learning as well as systems-based practice. Besides these, there are many other capabilities which are not formally taught but is learnt through observation, role- modelling or specific targeted opportunistic initiatives which may come about. In transitioning from junior residency (the first 3 years) into senior residency, there may be many challenges to negotiate. It is crucial for residents as well as faculty and supervisors to plan this transition and chart the course together, ensuring an open/ nurturing mentorship and relationship, which is as seamless as it can be.
\end{abstract}

Keywords: Emergency medicine; Residency; Professionalism; Conscious practice; Feedback

\section{Introduction and Background}

In Singapore, Emergency Medicine (EM) residency training according to the ACGME-I guidelines commenced in 2010. It provides structured and formative post-graduate training in EM. It aims to inculcate the fundamental knowledge, skills and humanistic qualities that make up the foundations of EM practice. (1) Residents will develop an expected level of clinical maturity, judgment and technical skills required to practice and also have the ability to incorporate ongoing updates and new knowledge as well as skills during their career. The training

is for 5 years; 3 years in junior residency and 2, in senior residency. There are three sponsoring institutions in Singapore: National Healthcare Group, National University Health System and Singapore Health (Singhealth) Services, with the latter usually taking in the higher numbers of residents each year. As the demand for Emergency Physicians increase, with the opening of new government and restructured hospitals, the intake for each of the institution has been increasing gradually $[1,2]$.

During the residency training, there are regular weekly training and teaching sessions. Some are institution specific whilst the others are planned at the national level (that means residents from all three programs come together for the session). There are assessments at strategic intervals and multiple key performance indicators these residents have to fulfill. The transition from junior to senior residency can be a significant and major milestone in the lives of these residents. They must meet certain minimum standard and criteria which have been set by the program and be versatile and capable of running the resuscitation room and the emergency department eventually. This transition in their medical life cycle can indeed be very stressful and uncertain, as they move on from being supervised to a supervising status $[1,3,4]$. 


\section{The Domains and their Challenges}

As residents' transition from junior to senior residency, their job scope, job performance and range of responsibilities given to them as well as the expectations pertaining to their performance evolve. Some may need time to adjust to these new responsibilities and roles they need to fulfill. Based on the observations made over the last 10 years, feedback from core faculty at Clinical Competency Committee meetings and review of residents' performance, certain challenges have been noted in the various domains of training. [1,4] The following section shares some of these observations.

\section{Medical Knowledge and Patient Care}

This domain is a fundamental which residents need to develop. The greater their range of exposures and experiential learning, the better will be their pattern recognition capabilities. This can vary across the residents entering senior residency. They must get used to managing patients with complex issues and multi-faceted problems. Therefore, for those with gaps in this domain, one on one training and supervision, using simulation-based learning as well as case-based discussions can be conducted. Senior residents are more independent in managing patients. They need not consult and review with faculty for all the cases they provide consultation. This also means a certain level of confidence must have been attained. The junior residency does have a strong emphasis on competencybased training and skills acquisition and by the time they reach senior residency level, they should be familiar and comfortable with all the requirements, provided they have satisfied the guidelines and met the minimum numbers for their logs [1,5-7]. Their clinical reasoning process must be sound. [6] In managing patients with common range of presentations, they should be able to anticipate the potential problems and complications. Recognition of the ill or deteriorating patient is also a necessary skill. When on duty, they need to demonstrate more adaptive capabilities and leadership, besides just being able to technically manage patients, one at a time [8]. Awareness of the available resources they can tap on as well as how to mobilize these when needed, for example in the situation of upsurge, is important. Their situational awareness capabilities must have been sharpening, from the many postings they would have gone through. At the same time, skills in interprofessional practice and systems-based practice are also highly necessary in view of the team-based work as well as collaborative practice in ED management of patients. Being able to execute all these seamlessly, is a rather big challenge, but in most programs, these senior residents are not left alone. They will be able to consult with faculty and attending. Supervision can be either in the form of direct supervision or indirect supervision, as appropriate for each resident.

\section{Communications}

Communications represent the cornerstone of practice. It can be the element that "make or break" an EP-patient or EP-others relationship. They have to communicate with other colleagues in the ED, both doctors and nurses, prehospital care providers such as paramedics, other discipline doctors, administrative staff and even make telephone calls as needed to other providers, perhaps also from other institutions. Today, expectations from patients and their families are very high, in terms of the care delivery, correspondence and professionalism of healthcare providers. Similarly, our residents will have to measure up and perform accordingly as well $[4,7]$.

As a senior resident, one has to be dynamic and adaptable in their communications responses in the ED. Things and action are moving fast and knowing what to say or 'not to say' under these circumstances can be crucial. Besides the verbal, the non-verbal communications skills play an important role as well. The people who work with the senior residents will provide 360 degrees feedback on their performance and a significant weightage and influence of this is based on their communications skills $[7,9]$.

The senior residents can be called upon to handle any communications issue the junior residents may not be able to handle. Thus, they must be versatile, be able to think fast, make the appropriate "damage control" explanation and conversations. There will also be occasions to make end of life decisions, with patients and family members. Not forgetting also, the documentation and typing or writing skills. These may be involved in patient record keeping and a high degree of vigilance and astuteness is needed. Of all the skills, good and effective communications capabilities is one of the most pertinent one $[9,10]$.

\section{Leadership}

The senior resident will start to take on more and more leadership roles. They will be supervising junior residents, leading resuscitation teams and will be consulted by colleagues and nurses in the event of doubts and uncertainties. They will be acting like the faculty (the faculty is around to be consulted and to supervise as well) and will also need to educate others on the job. Any opportunities to teach younger colleagues can be grabbed during "embedded learning". They will hold the senior doctor/ faculty on-call telephone and have to discuss regarding transfers and acceptance of patients from other institutions. They will be the role model on the shift, they may be the one doing the debriefing after challenging cases and act as the coordinator, who can re-allocate manpower to the different areas according to patient load and needs $[8,9]$. This means their situational awareness of how the ED is on their shift is spot-on and up to date. These roles that they have to fulfill can be daunting for a resident who has just stepped into senior residency year. They need to be proactive, adapt quickly, take charge and perform. It is a challenging role indeed and under the trained eye of the senior faculty, it is not difficult to pick up those who falter and non- performers $[8,11]$.

\section{Academic and Scholarly Activities}

Senior residency is still a training phase. Residents will continue to perform clinical work, be supervised accordingly, teach, conduct 
research and publish papers in peer-reviewed journals. They also have to attend the EMCC (Emergency Medicine Core Curriculum) weekly training, make presentations, attend conferences and many more. This is also similar to the lifelong continuing education they will have to go through. Senior residency is also the period when residents begin to realize which is/ are their areas of interest for sub-specialization eg. emergency cardiovascular care, trauma and disaster, pediatric emergency medicine, toxicology etc. From senior residency onwards, they can begin to establish themselves and their niche areas of research and interest as well $[1,4,11]$.

\section{Advocacy}

With the more adaptive leadership roles and views, senior residents now become aware of many other issues, which are spinoffs and may have either direct or indirect links with healthcare and health promotion. By now, they have to see the bigger picture of healthcare in their countries, region and the world [8].

Initiatives such as patient safety, quality care and standards, risk management, population determinants of health and healthcare will come to be on their radar. Some senior residents will find their passion in some of these areas and become advocates. They may then make representation of these topics to senior management, to non -governmental (NGOs) or even governmental agencies. They start to become advocates for change and for equality [1,11-12]. For example the author herself was an elected Member of Parliament in Singapore for 15 years, whilst she continued with her practice as an EP. During these periods, she championed multiple healthcare related issues and asked the relevant questions in Parliament, changed policies, brought on new guidelines and practices. Others will find the appropriate channels to make the necessary representations, which they come across in the course of their work at the frontline.

Senior residents will also begin to form collaboration with different groups and different disciplines. They will realize the importance of inter-professional collaborative practice. They will represent Emergency Medicine in some of these collaborations. They may even begin to be approached to be representatives on boards of NGOs and other relevant organizations. They may begin to speak up on a variety of topics and themes which appeal to them $[4,7]$.

\section{Professionalism}

This is not something new or only founded during senior residency. It is a follow through from the earlier training years. However now, their commitments and performance are closing up towards that of a faculty or attending. The judgment of their level of professionalism is multi-factorial and multi-faceted, incorporating elements such as good and upright clinical practice, ethics, integrity, camaraderie with colleagues, teamwork and partnerships, knowledge and confidence, amongst others. This is also where they begin to be more aware of their strengths and weaknesses in some of these areas $[12,13]$.

\section{The Challenges}

Besides medical knowledge and patient care domains which tend to be more technical, leadership, professionalism, role as educator and assessor or advocacy are not formally taught as didactic topics. There may be some topics such as "residents as teachers" incorporated into the curriculum, but even with this it may only cover the topic superficially. Residents will learn and acquire these capabilities by observing their seniors, by trial and error, by immersion and other informal platforms of exposure. This, they will have to do, amidst the time constraints and competing demands and priorities in the ED. Residents will try to find their own ways of coping and going through this [14-16] Some do this very well whilst others may struggle and may need more time. Supervisors will need to keep a keen eye on them and advise or intervene appropriately, in a timely fashion.

The use of dedicated supervising shifts can be useful but not many EDs can afford to grant residents and faculty, this time. Role modelling can be useful provided the appropriate faculty are available to help nurture and inculcate correct principles and values. To get around this, some centers come up with checklists on the topics and skills senior residents need to know and be trained in. In Singapore we use The Education Portfolio and The Administration Portfolio to help guide the senior residents on what capabilities, experiential learning and exposure they need to have under these categories. The Education Portfolio emphasizes on their involvement in small group teaching, large group learning activities, direct observation supervision, mentoring and coaching students and junior residents and even education involving the public, nursing colleagues and others [1]. Feedback must also be gotten for these involvements. Their personalized supervisor faculty will guide them and help with direction/ goals setting. For the Administration Portfolio, they are required to accomplish activities such as doing a root cause analysis, handling medication errors, risk management incident in the ED, handling complaints and even disaster and mass casualty responses $[1,14]$.

One of the useful initiatives for residents in training is to receive feedback. To be useful, the feedback from faculty should be specific, timely and targeted, with specific examples. Generic feedback such as 'keep up the good work', 'need to read more', 'need to show more confidence in talking to patients' may not have significant impact on the resident. Instead comments such as "resident is able to come up with a good set of differential diagnoses when discussing chest pain. He is able to read the electrocardiograph confidently to ensure acute coronary syndrome is being ruled out', may be more useful. Constructive feedback is encouraged. It can be difficult to provide negative feedback, but there are techniques to deliver this in which faculty can be trained. At times, the resident may not have insight into the problem, habit or working model that he/she has [14-16] Here is where the faculty need to assist with very concise, 
targeted inputs, with sound and concrete examples to illustrate the points. It is also similar to promoting the more conscious practice of medicine [17].

The EM senior resident has to go through a significant range of experiences and activities, and some may not be able to keep up. Thus, case by case review by their supervisors as well as the Clinical Competency Committee is conducted. Some may require a period of remediation, set with focused and targeted goals to complete the gaps in which ever domains they may lack [18]

\section{Recommendations}

Understanding the issues related with transitioning from junior to senior residency in EM is important, if we want to facilitate the process and assist our residents through this milestone in their medical lifecycle. The following are recommendations which can be implemented:

- To create awareness of the transition milestones to both faculty and residents. This is to encourage them to communicate more about it, share their concerns, fears and suggestions and have the faculty, together with the resident, come up with a specified targeted game plan for each resident. Focused group discussions can also be conducted for residents in their third year of junior residency, in preparation for the 'big jump'

- Incorporating some formal sessions on "how to supervise and assess junior residents/ colleagues can be very helpful

- Having dedicated 'partnership shifts' or 'piggy-back shifts' where the third-year residents can closely work with their personal supervisors and get detailed targeted feedback on their performance. These can be very useful as a form of on the job training, utilizing an apprentice-ship model. This helps to better prepare the resident for the transition

- The use of 'shift cards' is something we utilize at SingHealth, from the first year of residency training. This is a summarized report at the end of each shift, given to the resident by the faculty in-charge. It covers inputs in all the following domains: medical knowledge, patient care, professionalism, communications, evidence-based practice and systems-based practice. These shift cards are kept and compiled so the resident and faculty supervisor can review at regular intervals and assess their performance and the need for interventions.

- $\quad$ Case-based discussions are also very useful. The faculty will take the resident through a medical case and discuss all the relevant points/ domains. They will assist the resident through reflection as well.

- $\quad$ Orientation to the various resources that senior residents need to know and utilize

- Allowing gradual enhancement of the repertoire of privileges given to the resident, which may commence from the second half of their third year

- The option to use simulation where relevant to help get feedback points across or strengthen areas of weakness.

- Ensuring faculty and supervisors to residents attend sessions on how to give effective feedback

- $\quad$ Faculty can be a trusted friend to the resident besides just as a mentor/ supervisor. This way they can open up and share their deepest thoughts and concerns, which may be holding them back.

\section{Conclusion}

Senior residents have to integrate the continued development of their clinical acumen, with becoming a medical educator as well as an assessor. Their job scope has a broad spectrum and can be challenging; with the need to ace Medical Knowledge, Patient Care, Practice-based Learning, Professionalism, Communications and Systems-based Practice as core competencies. It is essential that planning and conceptualizing of the pathway be done to customize and facilitate the journey of our residents. This journey does not end there; because they will continue to incorporate new skills and knowledge during their careers and maintain their physical and psychological wellness.

\section{Acknowledgment}

None.

\section{Conflict of Interest}

No conflict of interest.

\section{References}

1. Lim BL (2013) Residency programmes in Singapore: challenges ahead. Annals Acad Med Singapore 42: 265-266.

2. ACGME-International. Singapore Health Services.

3. Khalife R, Gonsalves C, Code C, Halman S (2018) Transitioning towards senior medical resident: identification of the required competencies using consensus methodology. Can Med Edu J 9(3): e64-e75.

4. Kilbertus S, Pardhan K, Zaheer J, Bandiera G (2019) Transition to practice: evaluating the need for formal training in supervision and assessment among senior emergency medicine residents and new to practice emergency physicians. CJEM 21(3): 418-426.

5. Sacchetti A, Carraccio C, Harris RH (1992) Resident management of emergency department patients: is closer attending supervision needed? Ann Emerg Med 21(6): 749-52.

6. Lateef $F$ (2019) Clinical Reasoning: The core of medical education and practice. Int J of Internal and Emergency medicine 1(2): 1015.

7. Wong R (2012) Defining content for a competency based postgraduate curriculum (CANMeds) in ambulatory care. Can Med Edu J 3(1): e21-e32.

8. Lateef F (2018) Grace under pressure: Leadership in Emergency Medicine. Journal of Emergencies, Trauma and Shock 11(2): 73-79.

9. Kennedy TJ, Regehr G, Baker GR, Lingard LA (2005) Progressive independence in clinical training: a tradition worth defending? Acad Med 80(10 Suppl): S106-S111.

10. Orman SA, Thornton VJ (2010) Analysis of junior doctor supervision in Australasian emergency departments. Emerg Med Australas 22(4): 301339. 
11. Olmos-Vega F, Dolmans D, Donkers J, Stalmeijer RE (2015) Understanding how residents' preferences for supervisory methods change throughout residency training: a mixed methods study. BMC med Edu 15: 177.

12. Lateef F (2020) Through the ethical lenses: There is more than meets the eye with COVID 19. Archives of Emergency med and Intensive Care 3 (1): 6-16.

13. Bryden P, Ginsburg S, Kurabi B, Ahmed N (2010) Professing professionalism. Are we our own worst enemy? Faculty members experiences of teaching and evaluating professionalism in medical education at one school. Acad Med 85(6): 1025-1034.

14. Allen BR (2014) Transition to practice: From resident to faculty at the same institution. Journal of Graduate med Edu.
15. Bhat R, Takenaka K, Levine B (2015) Predictors of top performer during emergency medicine residency. J Emerg Med 49(4): 505-512.

16. Lateef F (2020) COVID 19 pandemic: Disruption or a fertile experiential learning platform for emergency medicine residents? Edu in Medicine Journal 12(3): 39-47.

17. Lateef $F$ (2016) The art of conscious practice: mastering medicine. Edu in Med Journal 8(2): 83-87.

18. Lateef F (2016) Remediation in Emergency medicine. What are the issues? Emergency Medicine Investigations. 